\title{
Pengaruh Temperatur Pada Microwave Pirolisis Cangkang Kelapa Sawit dan Low Density Polyethylene Dengan Katalis Zeolite/Kalsium Oksida
}

\section{The Effect of Microwave Temperature of Pyrolysis Shell Palm and Low-Density Polyethylene With Catalyst Zeolite and Calcium Oxide}

\author{
Maulana Wahyu Ayatullah ${ }^{1 *}$, Harwin Saptoadi ${ }^{2}$ \\ ${ }^{1,2}$ Departemen Teknik Mesin dan Industri, Universitas Gadjah Mada
}

\section{ARTICLE INFO}

Article history:

DOI:

$\underline{10.30595 / p s p f s . v 1 i .140}$

Submitted:

June 26, 2021

Accepted:

July 10, 2021

Published:

Oct 31, 2021

Keywords:

Palm Shell, Catalyst, LDPE, Microwave, Pyrolysis

\begin{abstract}
In general, the use of oil palm parts can be utilized by industry, but it is different from oil palm shells which become waste. The high use of plastic is proportional to the waste generated. So far, both types of waste are problems that have not been resolved. The utilization of waste shell waste and low-density polyethylene using the pyrolysis method. Microwave technology has been widely used as a heat source in the pyrolysis process. The advantages of using microwaves in pyrolysis are fast and selective heating, efficient energy use, and control of pyrolysis products. This study aimed to determine the characteristics of Pyrolytic-oil from the pyrolysis of waste oil palm shells and Low-density polyethylene. The research was conducted using a microwave with temperature variations of $400 \mathrm{oC}, 450 \mathrm{oC}, 500 \mathrm{oC}, 550 \mathrm{oC}$ and $600 \mathrm{oC}$. The composition of the main ingredients consisted of 75 grams of palm shells, 75 grams of low-density polyethylene plastic, 56.25 grams of a zeolite catalyst, 56.25 grams of calcium oxide and 131.25 grams of charcoal carbon absorber. The results showed the effect of temperature on pyrolytic-oil productivity; as the temperature increases, the product gas increases. The lowest density value at a temperature of $400 \mathrm{oC}$ is $966.8 \mathrm{Kg} / \mathrm{m}$. The lowest viscosity at a temperature variation of $500 \mathrm{oC}$ is 2.1 Mpa.s. The highest acidity value is at a temperature of $550 \mathrm{oC}$.
\end{abstract}

This work is licensed under a Creative Commons Attribution 4.0 International License.

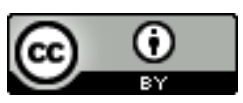

\section{Corresponding Author:}

Maulana Wahyu Ayatullah

Departemen Teknik Mesin dan Industri, Universitas Gadjah Mada

Jl. Senolowo, Sinduadi, Mlati Sleman, Daerah Istimewa Yogyakarta 5524 Telp. (0274) 521673

Email: maulana.w@mail.ugm.ac.id

\section{PENDAHULUAN}

Minyak sawit merupakan minyak nabati yang banyak dikonsumsi di dunia menandingi konsumsi lainnya pada tahun 2015. Sawit diekstraksi menjadi minyak sawit sebagai bahan beberapa produk seperti bahan makanan, produk perawatan (kosmetik) dan biofuel. Konsumsi minyak sawit pada industry makanan sebesar $72 \%$, produk perawatan $18 \%$ dan industry biofuel sebesar $10 \%$. Peningkatan jumlah produksi minyak sawit terjadi pada 2016 dengan jumlah 48,9 juta ton. Negara dengan produksi minyak sawit tertinggi di dominasi oleh Indonesia dan Malaysia sebesar 8590\% dari total produksi minyak sawit dunia pada tahun 2016 (Voora, Larrea, Bermudez, \& Baliño, 2019). Peningkatan yang sama dengan industri juga terjadi pada produksi plastik. Pada tahun 2018 produksi plastik mencapai 359 miliar ton, peningkatan dari tahun 2017 sebesar 9 miliar ton pada total produksi plastik dunia (Europe, Group Market Research, GmbH, \& Strategy, 2019). Indonesia mencatat 64 miliar ton sampah dimana 14\% merupakan sampah plastik atau sebesar 8,9 miliar ton (Lestari \& Trihadiningrum, 2019). 
Analisis ultimate cangkang kelapa sawit memiliki kandungan senyawa karbon sebesar 51,56\% sementara pada plastik low density polyethylene sebesar 85,83\% (Huang, Chen, Li, \& Xing, 2018). Senyawa polimer plastik low density polyethylene berasal dari minyak bumi. Pada analisis proximate nilai kalor plastik yang dihasilkan sebesar 43 MJ/kg dan cangkang kelapa sawit 18,81 MJ/kg (Abdul Wahid, Saleh, \& Abdul Samad, 2017). Sturuktur penyusun cangkang kelapa sawit yang terdiri dari hemiselulosa, selulosa dan lignin dapat diubah menjadi 6 jenis karbon atau hexose sugar (Ikumapayi \& Akinlabi, 2018).

Metode pirolisis merupakan dekomposisi biomassa dan bahan kimia dengan proses termal pada sistem tertutu dan kondisi tidak adanya oksigen. Proses pirolisis terjadi pada temperatur $300^{\circ} \mathrm{C}$ sampai $600{ }^{\circ} \mathrm{C}$. Proses termal membentuk reaksi komposisi biomassa menjadi produk gas, cair, padat (arang) (Basu, 2013). Teknologi microwave sebagai sumber termal terdiri dari gelombang elektrik dan magnetic. Transfer energi melalui gelombang mikro masuk pada struktur material sehingga proses termal yang dihasilkan menyesuaikan ukuran partikel material (Caroko, Saptoadi, \& Rohmat, 2020a). Laju pemanasan yang relative tinggi, volumetrik dan selektif memungkinkan dapat mengkontrol laju aliran volatile dan mereduksi senyawa asam (An, Tahmasebi, \& Yu, 2017).

Penambahan katalis zeolite berfungsi sebagai pemecah senyawa besar menjadi lebih kecil dalam poros permukaan. Struktur poros internal pada zeolite berfungsi sebagai saluran untuk selektif senyawa sehingga terjadi pemecahan senyawa dan mengurangi pembentukan asam karboksilat (Whyte, Loubar, Awad, \& Tazerout, 2015). Kalsium oksida sebagai katalis berfungsi mereduksi senyawa asam pada dan membentuk senyawa karbon dalam proses transertifikasi (Fanny, Subagjo, \& Prakoso, 2018).

\section{METODE PENELITIAN}

\section{Bahan utama}

Penelitian ini menggunakan bahan utama yaitu campuran dari biomassa (cangkang kelapa sawit) dan plastik low density polyethylene. Cangkang kelapa sawit digiling menggunakan mill pulverizer, kemudian diayak untuk mengumpulkan sampel dengan ukuran 6 - 20 mesh. Sampel cangkang kelapa sawit kemudian dikeringkan menggunakan oven microwave pada temperatur $100 \pm 5^{\circ} \mathrm{C}$ selama 1 jam guna mengurangi kandungan moisture dan air. Plastik low density polyethylene berupa kantong plastik sejenis dipotong dengan ukuran $\pm 2-3 \mathrm{~cm}$. Penggunaan material penyerap gelombang mikro (absorber) menggunakan arang tempurung kelapa yang telah digiling dan diayak. Pada setiap percobaan material absorber yang digunakan sebanyak 50\% dari total massa bahan utama dan katalis. Masing-masing sampel bahan utama ditimbang, cangkang kelapa sawit 75 gr, plastik low density polyethelene $75 \mathrm{gr}$, katalis $75 \%$ dari total massa bahan utama. Semua bahan utama dicampurkan secara manual dalam satu wadah, kemudian dimasukan kedalam satu wadah kuarsa.

\section{Alat dan prosedur penelitian}

Proses pirolisis dilakukan dengan menggunakan 2 buah reaktor yaitu reaktor primer dan reaktor sekunder sebagai sumber panas. Reaktor primer berfungsi sebagai reaktor bahan utama yaitu microwave Elektrolux model EMM2308X dengan daya 800 watt dan frekuensi gelombang 2,45 GHz. Reaktor sekunder berfungsi sebagai pemanas katalis yaitu modifikasi oven dengan wadah $8 \times 27 \mathrm{~cm}$. Air dimasukan ke dalam chiller untuk menjaga temperatur air, kemudian dialirkan kedalam pipa kondensor secara berlawanan dengan arah produk gas (contraflow) menggunakan pompa. Katalis dimasukan ke dalam reaktor sekunder. Sampel cangkang kelapa sawit dan plastik low density polyethyelene dimasukan pada wadah kuarsa sebagai wadah pada reaktor primer dengan kapasitas $1000 \mathrm{ml}$ terbuat dari material pyrex. Reaktor kuarsa dimasukan ke dalam microwave pada temperatur lingkungan kemudian variasi temperatur diatur melalui termokontroler yang tersambung dengan termokopel. Variasi temperatur pada reaktor primer diatur sama dengan pada reaktor sekunder yaitu temperatur $400{ }^{\circ} \mathrm{C}, 450{ }^{\circ} \mathrm{C}, 500{ }^{\circ} \mathrm{C}, 550{ }^{\circ} \mathrm{C}$ dan $600^{\circ} \mathrm{C}$. Untuk menjaga atmosfir inert (tanpa oksigen) pada proses pirolisis maka digunakan gas nitrogen yang disambungkan melalu selang menuju kedalam reaktor dengan laju 1,5 L/menit. Microwave dinyalakan ketika temperatur katalis mencapai temperatur konstan sesuai standar variasi. Daya pada microwave sebagai reaktor primer diatur pada $800 \mathrm{~W}$ selama 40 menit. Erlenmeyer digunakan sebagai wadah penampung produk cair selama proses pirolisis. Pencatatan waktu dan fenomena pada proses pirolisis dilakukan setiap menit. Diagram skema dapat dilihat pada gambar 1.

Degradasi termal biomassa menggunakan cangkang kelapa sawit dan polimer plastik low density polyethylene. Sebanyak 225 gr sampel dimasukan ke dalam wadah reaktor kuarsa untuk setiap percobaan selama 40 menit . Sampel cangkang kelapa sawit dicampur terlebih dahulu dengan plastic low density polyethylene dan absorber arang cangkang kelapa dengan perbandingan massa 1:1:1. Katalis zeolite sebanyak 56,25 gr dicampurkan dengan kalsium oksida sebanyak 56,25 gr terlebih dahulu kemudian dimasukan kedalam reaktor sekunder hingga mencapai temperatur variasi.

Pemisahan produk arang, cair, dan katalis dilakukan ketika pirolisis selesai dan temperatur turun pada temperatur lingkungan. Masing - masing produk pirolisis ditimbang dan produk cair (pyrolytic-oil) kemudian melalui proses pengujian densitas, tingkat keasaman dan tingkat kekentalan (viskositas). 


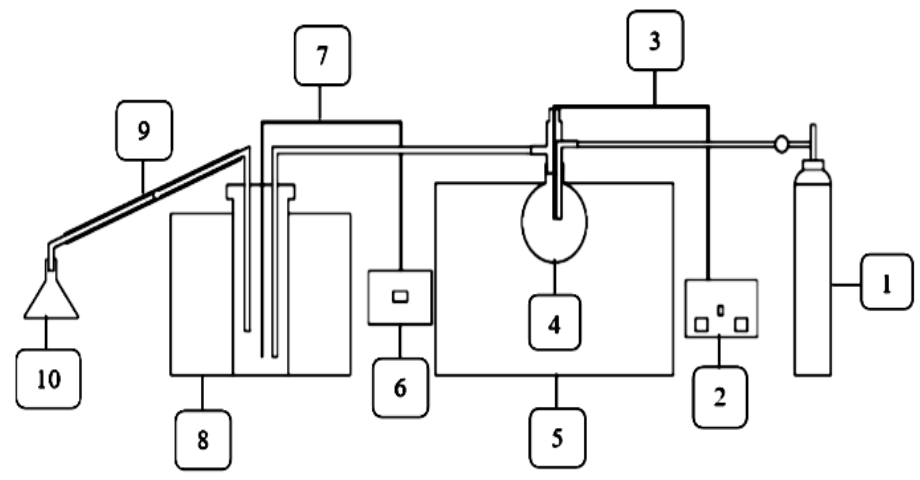

Keterangan :

1. Tabung gas nitrogen

2. Thermocontroller reaktor primer

3. Thermocouple reaktor primer

4. Reaktor kuarsa (tabung pyrex)

5. Reaktor primer

6. Thermocontroller reaktor sekunder

7. Thermocouple reaktor sekunder

8. Reaktor sekunder

9. Pipa kondensor

10. Wadah penampung erlenmeyer

Gambar 1. Skema instalasi alat

\section{Metode pengujian}

Pengukuran densitas dilakukan guna mengidentfikasi massa jenis pyrolytic-oil dan juga mengukur kuantitas produk pirolisis. pengukuran dilakukan menggunakan persamaan berikut:

Densitas Pyrolytic-Oil $=$ Massa Pyrolytic-Oil $(\mathrm{gr}) /$ Volume $(\mathrm{ml})$

Massa Gas = Massa Biomassa(gr) $-($ Massa bio-oil+Massa Arang $)$.

(2) Kuantitas

Pyrolytic-Oil $=($ Massa Pyrolytic-Oil $/$ Massa Biomassa $) \times 100 \%$ (Massa Arang / Massa Biomassa) $) \times 100 \%$

Massa Biomassa) $\times 100 \%$.

(3) Kuantitas Arang =

Pengujian kekentalan (viskositas) guna mengetahui tingkat kekentalan pyrolytic-oil. Proses pengujian dilakukan menggunakan Brookfield viscometer digital DV-II + pro. Sebanyak $20 \mathrm{ml}$ pyrolytic-oil dituangkan pada wadah, kemudian spindle type 1 dicelupkan kedalam wadah. Pengujian dilakukan dengan menggunakan kecepatan putar spindle 60 rpm selama 10 menit.

Pengujian nilai keasaman dilakukan guna mengetahui nilai keasamaa pyrolytic-oil hasil pirolisis. Metode pengujian menggunakan Pen type $\mathrm{pH}$ meter 009(1)A. Kalibrasi terlebih dahulu dilakukan menggunakan bubuk pH dengan keasaman $4.00 @ 25^{\circ} \mathrm{C}$ yang dilarutkan kedalam ait sebanyak $250 \mathrm{ml}$. alat kemudian dicelupkan kedalam pyrolytic-oil hingga nilai $\mathrm{pH}$ steady.

\section{HASIL DAN PEMBAHASAN}

\section{Temperatur microwave pirolisis}

Microwave pirolisis cangkang kelapa sawit dan low density polyethylene pada daya $800 \mathrm{~W}$ dengan variasi temperatur $400^{\circ} \mathrm{C}, 450^{\circ} \mathrm{C}, 500^{\circ} \mathrm{C}, 550^{\circ} \mathrm{C}$, dan $600{ }^{\circ} \mathrm{C}$. Input daya microwave mempengaruhi laju penamanasan pada proses pirolisis. Daya sebesar $800 \mathrm{~W}$ mempengaruhi laju pemanasan peningkatan temperatur antara $1 \mathrm{dan} 3^{\circ} \mathrm{C} / \mathrm{s}(60-$ $90^{\circ} \mathrm{C} / \mathrm{min}$ ) (Klinger et al., 2018). Pada gambar 2 menunjukan bahwa variasi temperatur $600 \mathrm{oC}$ laju pemanasan mencapai temperatur maksimal pada menit ke 20. Fenomena tersebut juga terjadi pada variasi temperatur $400^{\circ} \mathrm{C}$ dan temperatur dalam keadaan steady. Tingginya laju pemanasan pada microwave pirolisis disebabkan oleh energi gelombang mikro yang terserap oleh absorber dan pada waktu yang bersamaan juga mempertahankan keseragaman temperatur pada sampel. Laju pemanasan menurun terjadi antara temperatur $110-210^{\circ} \mathrm{C}$, secara signifikan terjadi pada variasi $450^{\circ} \mathrm{C}$ dan $550^{\circ} \mathrm{C}$. Fenomena tersebut disebabkan oleh degradasi senyawa moisture dan proses dekomposisi hemiselulosa pada cangkang kelapa sawit (Asadullah et al., 2014). Moisture merupakan senyawa tinggi akan kandungan oksigenat terdiri dari senyawa oksigen dan hidrogen (Wilson, Tremain, \& Moghtaderi, 2018). Laju pemanasan pada tahap ini bergantung pada panas yang ditransfer pada material, sehingga tingkat kestabilan temperatur membutuhkan waktu yang lebih lama (Caroko, Saptoadi, \& Rohmat, 2020b). Campuran plastik low density polyetylene juga mempengaruhi peningkatan temperatur microwave pirolisis. Nilai densitas plastik low density polyethylene yaitu $0,922 \mathrm{~g} \mathrm{~cm}-3$ lebih rendah dibandingkan densitas cangkanga kelapa sawit (Švorčík et al., 2006). (Amini, Ohno, Maeda, \& Kunitomo, 2018) menyatakan bahwa semakin rendah nilai densitas, peningkatan temperatur semakin cepat. Oleh karena itu kepadatan material juga mempengaruhi laju pemanasan. 


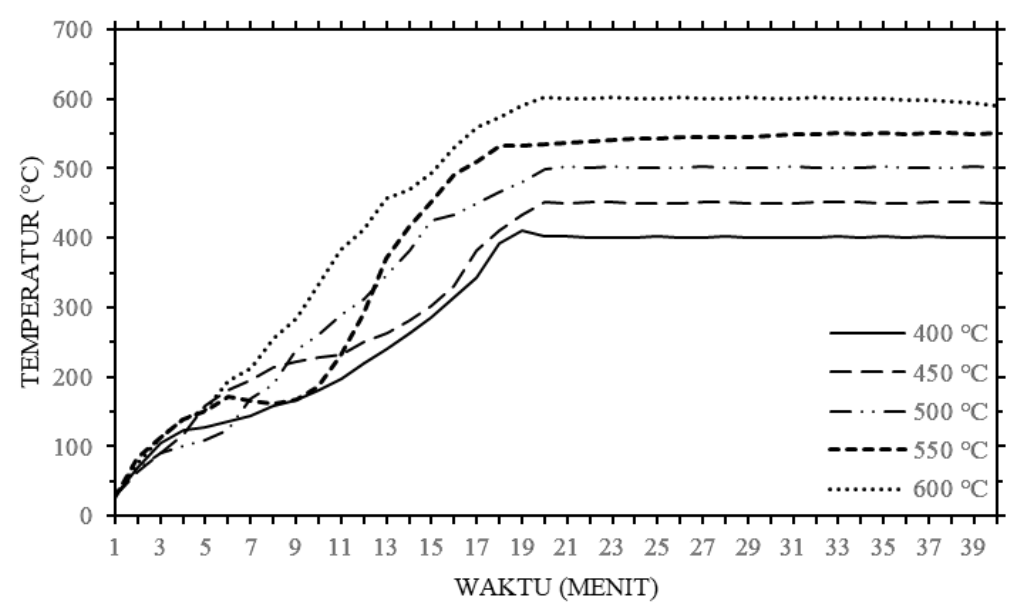

Gambar 2. Temperatur microwave pirolisis

\section{Pengaruh temperatur terhadap kuantitas}

Produk pirolisis dipengaruhi oleh temperatur maksimal. Semakin tinggi temperatur maka produk padat (arang) akan menurun dan produk gas mengalami peningkatan. Pada gambar 3 peningkatan produk gas searah dengan peningkatan produk pyrolytic-oil. Peningakatan produk gas disebabkan oleh termal cracking pada proses microwave pirolisis. Termal cracking merupakan reaksi pemecahan rantai karbon membentuk ikatan senyawa rantai karbon baru. Pada temperatur $400 \mathrm{oC}$ proses pirolisis persentase produk arang tinggi yang disebabkan oleh lambatnya laju dekomposisi termal. Temperatur dekomposisi pirolisis biomasssa pada temperatur rendah $(<350 \mathrm{oC})$ menghasilkan produk fase padat yang tinggi. Searah dengan peningkatan temperatur $450 \mathrm{oC}$ ke $500 \mathrm{oC}$ meningkatkan produk cair (pyrolytic-oil) sebesar 14,5\%, namun pada temperatur $600 \mathrm{oC}$ produk cair mengalami penurunan menjadi $12,8 \%$. Penurunan produk cair dan peningkatan produk gas pada temperatur $600 \mathrm{oC}$ disebabkan proses secondary cracking produk cair menjadi gas pada temperatur tinggi (Kumar, Panda, \& Singh, 2010). Penurunan produk arang pada temperatur $450 \mathrm{oC}$ ke $660 \mathrm{oC}$ sebesar $27,3 \%$. Penurunan produk arang pada peningkatan temperatur disebabkan oleh dekomposisi primer biomassa yang terjadi pada temperatur yang lebih tinggi.

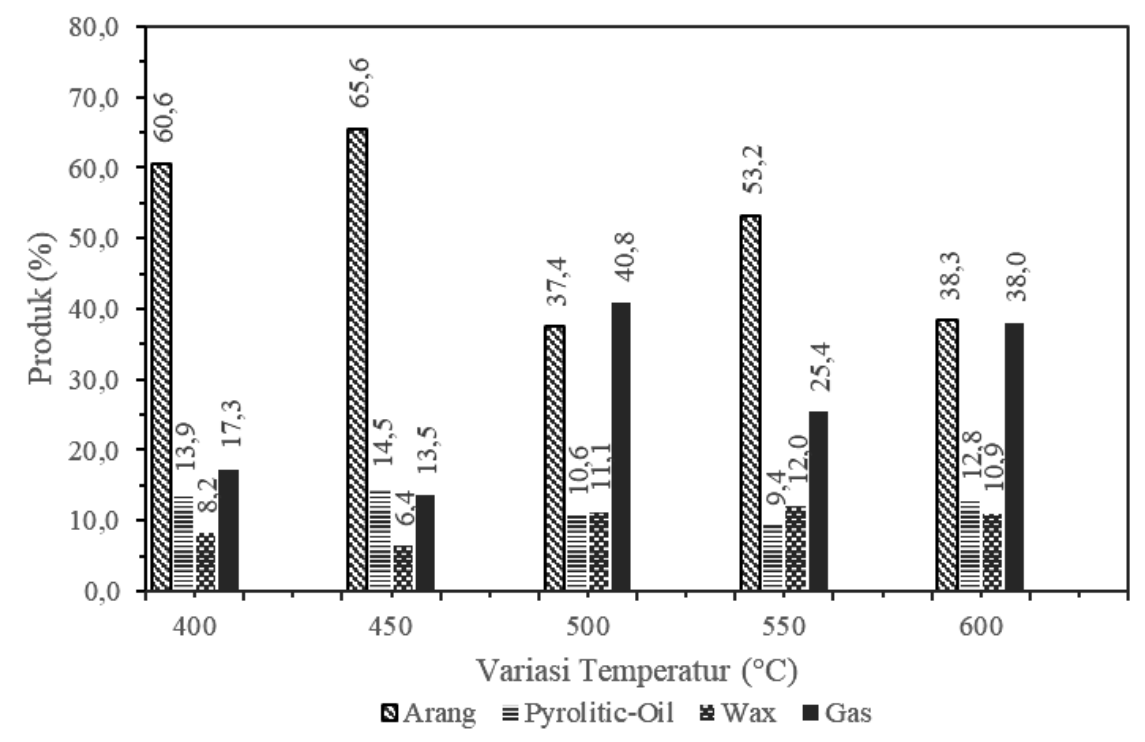

Gambar 3. Kuantitas produk microwave pirolisis

Pembentukan wax selama proses pirolisis disebabkan oleh pemecahan ikatan rantai karbon pada plastik low density polyethylene menjadi rantai panjang. Tingginya laju pemanasan menyebabkan laju reaksi plastik low density polyethylene terdekomposisi lebih cepat. Dekomposisi low density polyethylene terdorong oleh gas hidrogen ke arah kondensasi dan membentuk wax (Thoharudin et al., 2018). Peningkatan produk wax mengalami terjadi pada variasi temperatur $450^{\circ} \mathrm{C}, 500{ }^{\circ} \mathrm{C}$ dan $550{ }^{\circ} \mathrm{C}$. Hal tersebut disebabkan oleh reaksi secondary cracking yang terjadi pada temperatur tinggi (Ludlow-Palafox \& Chase, 2001).

Pengaruh temperatur pada densitas pyrolytic-oil 
Nilai densitas menunjukan massa jenis pyrolytic-oil microwave pirolisis ditunjukan pada gambar 4 . Semakin rendahya nilai densitas yang diperoleh maka akan semakin ringan pyrolytic-oil dan sebaliknya jika nilai desitas semakin besar maka pyrolytic-oil akan semakin berat. Pada gambar 4 massa jenis terendah pada temperatur $400^{\circ} \mathrm{C}$ yaitu sebesar $966,8 \mathrm{Kg} / \mathrm{m}^{3}$ dan tertinggi pada temperatur $450{ }^{\circ} \mathrm{C}$ yaitu $1021,7 \mathrm{Kg} / \mathrm{m}^{3}$. Temperatur menyebabkan dekomposisi strukutur hemiselulosa, selulosa dan lignin membentuk senyawa oksigenat diatas temperatur $450{ }^{\circ} \mathrm{C}$. Semakin tinggi senyawa oksigenat yang terkondensasi juga meningkatkan nilai densitas. Nilai massa atom oksigen $0,71 \mathrm{Kg} / \mathrm{m}^{3}$ dan karbon sebesar 0,53 Kg/m³ (Ma, Zeng, \& Duan, 2019). Penggunaan katalis zeolit dan kalsium oksida berfungsi sebagai pemecah senyawa oksigenat. Hal tersebut disebabkan oleh struktur penyusun zeolit memiliki rongga yang berfungsi sebagai pemecah oksigen.

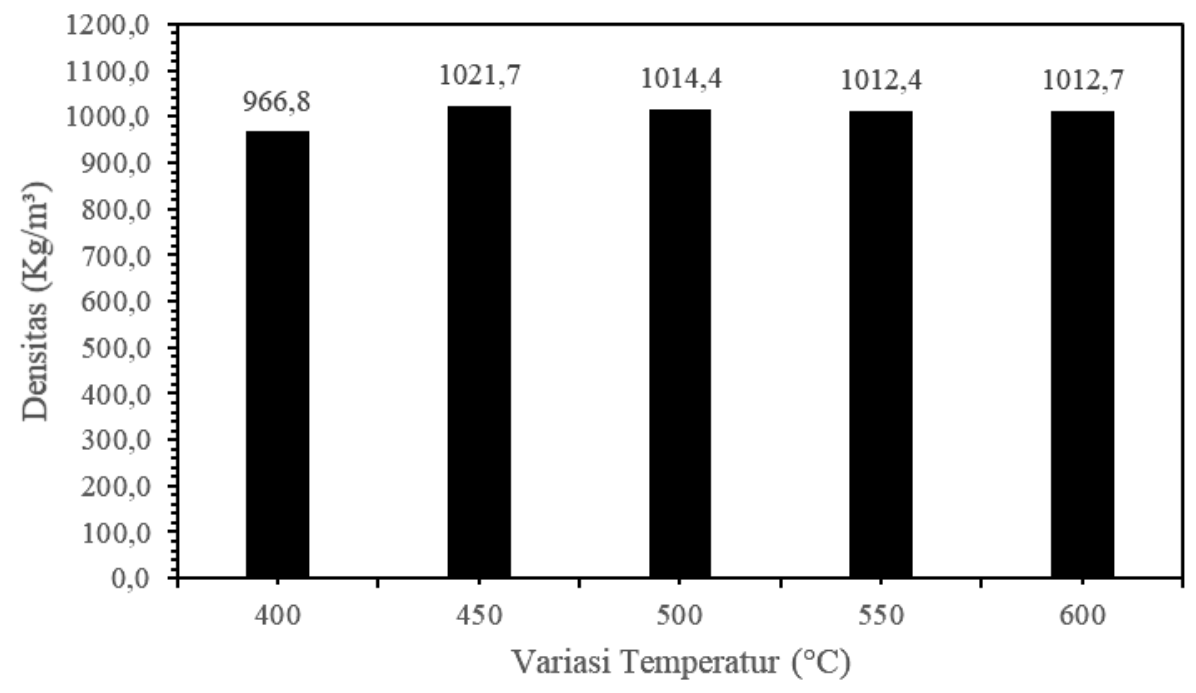

Gambar 4. Pengaruh temperatur pada densitas pyrolytic-oil

\section{Pengaruh temperatur pada viskositas pyrolytic-oil}

Nilai viskositas merupakan indikator tinggal kekentalan pyrolytic-oil. Pada gambar 5 menunjukan semakin tinggi variasi temperatur maka nilai viskositas akan semakin naik. Proses dekomposisi senyawa karbon dan dibantu oleh gas inert sehingga pembentukan rantai karbon terjadi dengan cepat. Sebaliknya rendahnya nilai viskositas disebabkan pembentukan rantai karbon yang relatif pendek. Setiap faktor pada proses pirolisi yang dapat memecah produk cair menjadi molekul dengan massa jenis yang lebih rendah, menyebabkan viskositas rendah. Dekomposisi senyawa volatil pada cangkang kelapa sawit mendorong pembentukan senyawa rantai karbon dibantu gas hidrogen.

Reaksi secondary cracking terjadi pada temperatur tinggi membentuk senyawa $\mathrm{H} 2 \mathrm{O}$ sehingga membentuk kadar air yang tinggi. Perbedaan nilai viskositas juga disebabkan oleh komposisi dan struktur bahan utama yang berbeda.

Pirolisis campuran plastik menghasilkan produk cair dengan viskositas rendah yang terdiri dari stirena dan hidrokarbon aromatik (Siddiqui \& Redhwi, 2009). Pada temperatur 400oC nilai viskositas sebesar 2,1 Mpa.s dan mengalami peningkatan searah peningkatan temperatur. Reaksi termal cracking dapat terjadi pada temperatur rendah, dan reaksi secondary cracking terjadi pada temperatur tinggi.

Pada variasi temperatur $600 \mathrm{oC}$ nilai viskositas pyrolytic-oil yaitu sebesar 2,6 Mpa.S. Hal tersebut disebabkan oleh proses decarbonilasi dimana rantai karbon terdekomposisi kembali. Katalis zeolit berfungsi sebagai penghasil karbon monoksida pada reaksi dehidrasi dan membentuk gas, sehingga menurunkan kadar air pada pyrolysis-oil. Zeolit juga berpengaruh menjadi material selektivitas molekul yang terjadi pada bagian internal poripori katalis. Hal tersebut menyebabkan degradasi molekul pada permukaan dan membentuk ikatan rantai pendek (Lee, 2009). Struktur penyusun pada pyrolytic-oil mempengaruhi nilai viskositas yang disebebkan oleh perbedaan temperatur dekomposisi bahan utama. Dekomposisi hemiselulosa, selulosa dan lignin terjadi pada temperatur rendah $(<400 \mathrm{oC})$ membentuk pyrolytic-oil dengan senyawa oksigenat sebelum temperatur maksimal. 


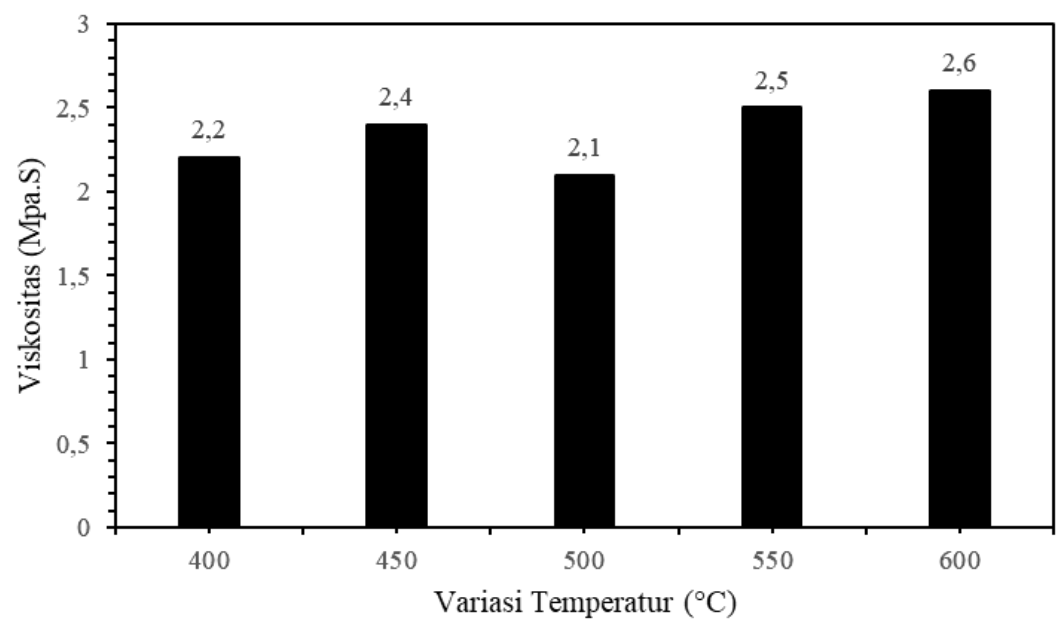

Gambar 5. Pengaruh temperatur pada nilai viskositas pyrolytic-oil

\section{Pengaruh temperatur pada keasaman pyrolytic-oil.}

Dekomposisi hemiselulosa, selulosa dan lignin pada cangkang kelapa sawit merupakan senyawa utama pembentukan asam pada pyrolytic-oil. Senyawa hidroksida membentuk hidrogen membentuk ion $\mathrm{H}+$ membentuk senyawa asam. Laju pemanasan microwave pirolisis $30-90^{\circ} \mathrm{C} / \mathrm{min}$ membentuk reaksi dekomposisi lignin menjadi senyawa fenol. Pelepasan ion $\mathrm{H}+$ pada senyawa hidrogen membentuk senyawa asam yang dapat terkondensasi. Pada gambar 6 menunjukan penurunan nilai keasaman relatif konstan pada temperatur $400^{\circ} \mathrm{C}, 450{ }^{\circ} \mathrm{C}$ dan $500{ }^{\circ} \mathrm{C}$ yaitu sebesar $0,1 \mathrm{pH}$. Pengaruh gelombang microwave meningkatkan laju pemasanan pada temperatur lebih tinggi sehingga pembentukan asam terjadi pada waktu singkat. Peningkatan nilai keasaman pyrolytic-oil terjadi pada variasi temperatur $550^{\circ} \mathrm{C}$ yaitu $5 \mathrm{pH}$ dan $600^{\circ} \mathrm{C}$ sebesar $4,8 \mathrm{pH}$. Dekomposisi katalis kalsium oksida terjadi pada temperatur antara $500 \mathrm{oC}$ dan $600{ }^{\circ} \mathrm{C}$. (Karunadasa, Manoratne, Pitawala, \& Rajapakse, 2019). Kalsium oksida berfungsi mereduksi senyawa asam dan karbon dalam proses transertifikasi. Selama proses katalitik, zeolite mengurangi pembentuan senyawa asam. Reaksi katalis kalsium oksida menghasilkan reaksi netralisasi dimana memecah senyawa asam menjadi kalsium karbonat dan membentuk keton. Struktur kerangka dan ukuran pori-pori zeolit bersifat netral dan bermuatan, hal ini mereduksi senyawa asam pada permukaan (Whyte et al., 2015). Zeolit alam pada pembentukan senyawa asam dimana reaksi decarboxylasi menghilangkan senyawa karboksil asam $(\mathrm{COOH})$ dan melepaskan senyawa oksigen. Proses tersebut diawali aktivasi katalis pada temperatur antara $500^{\circ} \mathrm{C}$ dan $650{ }^{\circ} \mathrm{C}$.

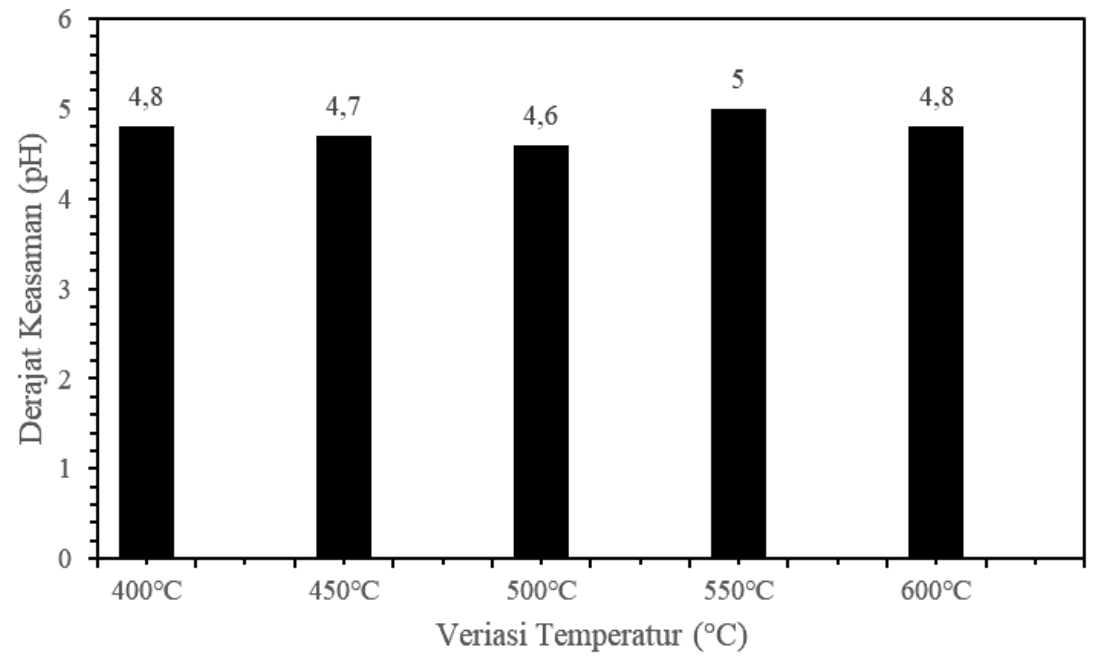

Gambar 6. Pengaruh temperatur pada nilai keasaman pyrolytic-oil

\section{KESIMPULAN}

Pada penelitian ini, temperatur berpengaruh pada microwave pirolisis cangkang kelapa sawit dan plastik low density polyethylene dan katalis zeolite/kalsium oksida. Peningkatan temperatur searah dengan peningktan produk gas, namun tinggi akan gas yang tidak dapat terkondensasi. Penurunan produk arang terjadi pada temperatur $600{ }^{\circ} \mathrm{C}$ yaitu sebesar $38,3 \%$, dengan produk pyrolytic-oil yaitu $12,9 \%$. Persentase produk pyrolytic-oil tertinggi terdapat pada variasi temperatur $450^{\circ} \mathrm{C}$ yaitu $14,5 \%$ dan $400{ }^{\circ} \mathrm{C}$ sebesar $13,9 \%$. Produktivitas produk pirolisis dipengaruhi oleh laju 
pemanasan dan temperatur. Semakin tinggi temperatur maka laju pemanasan akan semakin tinggi dan degradasi cangkang kelapa sawit dan plastik low density polyethylene semakin cepat. Nilai densitas pyrolytic-oil terendah pada $400{ }^{\circ} \mathrm{C}$ yaitu $966,8 \mathrm{Kg} / \mathrm{m}^{3}$, yang disebabkan oleh dekomposisi hemiselulosa dan selulosa pada temperatur rendah. Nilai viskositas tertinggi pada temperatur $600^{\circ} \mathrm{C}$ sebesar $2,6 \mathrm{Mpa} . \mathrm{S}$, yang disebabkan proses decarboxylasi senyawa karbon terdekomposisi kembali membentuk ikatan karbon rantai panjang pada temperatur tinggi. Peningkatan nilai keasaman terjadi pada variasi temperatur $550^{\circ} \mathrm{C}$ dan $600{ }^{\circ} \mathrm{C}$. Dekomposisi katalis kalsium oksida terjadi antara temperatur $500{ }^{\circ} \mathrm{C}$ dan $600{ }^{\circ} \mathrm{C}$ sehingga mereduksi pembentukan senyawa asam. Temperatur mempengaruhi laju reaksi dekomposisi bahan utama dan aktivasi katalis selama proses pirolisis.

\section{DAFTAR PUSTAKA}

Abdul Wahid, F. R. A., Saleh, S., \& Abdul Samad, N. A. F. (2017). Estimation of Higher Heating Value of Torrefied Palm Oil Wastes from Proximate Analysis. Energy Procedia, 138, 307-312.

Amini, A., Ohno, K., Maeda, T., \& Kunitomo, K. (2018). Effect of particle size and apparent density on the initial stages of temperature increase during the microwave heating of Fe3O4. Powder Technology, 338, 101109.

An, Y., Tahmasebi, A., \& Yu, J. (2017). Mechanism of synergy effect during microwave co -pyrolysis of biomass and lignite. Journal of Analytical and Applied Pyrolysis, 128(October), 75-82.

Asadullah, M., Adi, A. M., Suhada, N., Malek, N. H., Saringat, M. I., \& Azdarpour, A. (2014). Optimization of palm kernel shell torrefaction to produce energy densified bio-coal. Energy Conversion and Management, 88,1086-1093.

Basu, P. (2013). Biomass Gasification, Pyrolysis and Torrefaction: Practical Design and Theory. Biomass Gasification, Pyrolysis and Torrefaction: Practical Design and Theory (Second Edi.). United States of America: Elsevier.

Caroko, N., Saptoadi, H., \& Rohmat, T. A. (2020a). A Review on Microwave-Assisted Co-Pyrolysis of BiomassPolymers. International Review of Mechanical Engineering (IREME), 14(May), 339-350.

Caroko, N., Saptoadi, H., \& Rohmat, T. A. (2020b). Comparative study on the drying of oil palm solid waste using conventional and microwave methods. Journal of Engineering Science and Technology, 15(4), 2696-2711.

Europe, P., Group Market Research, GmbH, \& Strategy, C. M. \&. (2019). Plastics - the Facts 2019. An analysis of European plastics production, demand and waste data, 14, 35.

Fanny, W. A., Subagjo, S., \& Prakoso, T. (2018). Pengembangan katalis Kalsium Oksida untuk sintesis biodiesel.Jurnal Teknik Kimia Indonesia, 11(2), 66.

Huang, Y. W., Chen, M. Q., Li, Q. H., \& Xing, W. (2018). A critical evaluation on chemical exergy and its correlation with high heating value for single and multi-component typical plastic wastes. Energy, 156, 548-554.

Ikumapayi, O. M., \& Akinlabi, E. T. (2018). Composition, characteristics and socioeconomic benefits of palm kernel shell exploitation-an overview. Journal of Environmental Science and Technology, 11(5), 220-232.

Karunadasa, K. S. P., Manoratne, C. H., Pitawala, H. M. T. G. A., \& Rajapakse, R. M. G. (2019). Thermal decomposition of calcium carbonate (calcite polymorph) as examined by in-situ high-temperature X-ray powder diffraction. Journal of Physics and Chemistry of Solids, 134(May), 21-28.

Klinger, J. L., Westover, T. L., Emerson, R. M., Williams, C. L., Hernandez, S., Monson, G. D., \& Ryan, J. C. (2018). Effect of biomass type, heating rate, and sample size on microwave-enhanced fast pyrolysis product yields and qualities. Applied Energy, 228(July), 535-545.

Kumar, G., Panda, A. K., \& Singh, R. K. (2010). Optimization of process for the production of bio -oil from eucalyptus wood. Ranliao Huaxue Xuebao/Journal of Fuel Chemistry and Technology, 38(2), 162-167. Institute of Coal Chemistry, Chinese Academy of Sciences.

Lee, K. H. (2009). Thermal and catalytic degradation of pyrolytic oil from pyrolysis of municipal plasti c wastes. Journal of Analytical and Applied Pyrolysis, 85(1-2), 372-379.

Lestari, P., \& Trihadiningrum, Y. (2019). The impact of improper solid waste management to plastic pollution in Indonesian coast and marine environment. Marine Pollution Bulletin, 149(August), 110505.

Ludlow-Palafox, C., \& Chase, H. A. (2001). Microwave-induced pyrolysis of plastic wastes. Industrial and Engineering Chemistry Research, 40(22), 4749-4756. 
Ma, Y., Zeng, K., \& Duan, T. (2019). Fast and clean determination of total selenium in biological materials by an improved oxygen flask combustion method combined with hydride generation atomic fluorescence spectrometry. Microchemical Journal, 148(January), 743-747.

Siddiqui, M. N., \& Redhwi, H. H. (2009). Pyrolysis of mixed plastics for the recovery of useful products. Fuel Processing Technology, 90(4), 545-552.

Švorčík, V., Kolářová, K., Slepička, P., Macková, A., Novotná, M., \& Hnatowicz, V. (2006). Modification of surface properties of high and low density polyethylene by Ar plasma discharge. Polymer Degradation and Stability, 91(6), 1219-1225.

Thoharudin, Nadjib, M., Agung Santosa, T. H., Juliansyah, Zuniardi, A., \& Shihabudin, R. (2018). Properties of co pyrolysed palm kernel shell and plastic grocery bag with $\mathrm{CaO}$ as catalyst. IOP Conference Series: Earth and Environmental Science, 209(1).

Voora, V., Larrea, C., Bermudez, S., \& Baliño, S. (2019). Global Market Report : Palm Oil. International Institute for Sustainable Development., 16.

Whyte, H. E., Loubar, K., Awad, S., \& Tazerout, M. (2015). Pyrolytic oil production by catalytic pyrolysis of refusederived fuels: Investigation of low cost catalysts. Fuel Processing Technology, 140, 32-38.

Wilson, F., Tremain, P., \& Moghtaderi, B. (2018). Characterization of Biochars Derived from Pyrolysis of Biomass and Calcium Oxide Mixtures. Energy and Fuels, 32(4), 4167-4177. 